\section{Estudo \\ Ecidebate}

em Testão

Plamejamento
Revista Estudo \& Debate, Lajeado, v. 25, n. 3, 2018. ISSN 1983-036X

DOI: http://dx.doi.org/10.22410/issn.1983-036X.v25i3a2018.1638

\title{
COREDE MISSÓES: SUAS ESPECIFICIDADES E ESTRATÉGIAS DE DESENVOLVIMENTO
}

\author{
Micheli dos Santos ${ }^{1}$, Francisco Angst ${ }^{2}$, Letiane Peccin Ristow ${ }^{3}$
}

\begin{abstract}
Resumo: A regionalização do estado do Rio Grande do Sul através da instituição dos COREDEs considerou a existência de inúmeras diferenças entre as regiōes, sejam elas de ordem econômica, social, cultural ou de recursos naturais, com o objetivo de possibilitar o desenvolvimento através de políticas públicas que considerem as especificidades de cada região. Considerando a atuação dos COREDEs em diferentes regióes do estado o foco deste estudo é o COREDE Missóes, e as estratégias deste Conselho Regional para a promoção do desenvolvimento de sua área de abrangência. Para tanto realizou-se uma análise temática, com o objetivo de abordar o desenvolvimento regional e as estratégias de desenvolvimento construídas no Fórum de Discussão do COREDE Missóes. Os resultados indicam que os Conselhos Regionais que recebem maior apoio das Universidades locais tem assegurado maior credibilidade para seu trabalho, uma vez que encaram estas atividades como um instrumento de integração com a comunidade e regiáo de atuaçáo. No caso do COREDE Missóes, o suporte das universidades impacta positivamente, pois em sua regiáo de abrangência encontram-se instaladas e atuantes universidades privadas, bem como uma universidade federal (UFFS), conquistada inclusive através de políticas públicas que visam o desenvolvimento da regiáo.
\end{abstract}

Palavras-chave: Desenvolvimento Regional. Regionalização. COREDE Missões.

\section{COREDE MISSÓES: ITS SPECIFICITIES AND DEVELOPMENT STRATEGIES}

\begin{abstract}
The regionalization of the state of Rio Grande do Sul through the institution of the COREDEs considered the existence of innumerable differences between the regions, as economic, social, cultural or natural resources, with the objective of enabling development through specific public policies that consider the specificities of each region. Considering the performance of COREDEs in different regions of the state, the focus
\end{abstract}

1 Mestra em Desenvolvimento e Políticas Públicas (UFFS) - Cerro Largo, RS. Especialista em Administração Estratégica (UNIASSELVI). Bacharel em Administração (URI).micheli.santos@uffs.edu.br

2 Mestrando do Programa de Pós-Graduação Stricto Sensu em Desenvolvimento e Políticas Públicas (UFFS) - Cerro Largo, RS. Especialista em Educação à Distância (Serviço Nacional de Aprendizagem Comercial RS). francisco.angst@uffs.edu.br

3 Mestra em Desenvolvimento e Políticas Públicas (UFFS) - Cerro Largo, RS. Especialista em Desenvolvimento Rural Sustentável e Agricultura Familiar (UFFS). Graduada em Desenvolvimento Rural e Gestão Agroindustrial - UERGS. letiane.peccin@uffs.edu.br 
of this study is COREDE Missóes, and the strategies of this Regional Council to promote the development of its area of coverage. For this, a thematic analysis was carried out with the objective of approaching the regional development theme and the development strategies built in the COREDE Missóes Discussion Forum. The results indicate that the Regional Councils that receive greater support from the local Universities have ensured greater credibility for their work, since they consider these activities as an instrument of integration with the community and region of activity. In the case of COREDE Missóes, the support of the Universities has a positive impact, since in its region of coverage there are installed and active private universities, as well as a Federal University (UFFS), conquered even through public policies aimed at the development of the region.

Keywords: Regional development. Regionalization. COREDE Missōes.

\section{INTRODUÇÃO}

A temática do desenvolvimento tem sido amplamente discutida nas últimas décadas, inclusive gerando controvérsias quanto ao que realmente venha a ser desenvolvimento. No âmbito dos debates pesquisadores tem arguido de diversas formas tentando justificar suas teses que buscam o significado para a questão.

Neste contexto, a tônica que permeia o desenvolvimento local e regional têm se destacado, abordando diversos enfoques, como o social, sustentável, humano, ambiental e endógeno, além do econômico. O que percebe-se é que alguns destes enfoques tem sido superados, enquanto outros fortalecidos, inclusive com o estabelecimento de políticas públicas para articulação do desenvolvimento das regióes, considerando suas especificidades com o objetivo de evidenciar suas potencialidades (RESENDE, 2013).

Assim, as políticas passaram a ser elaboradas em diferentes escalas, abandonando o procedimento tradicionalmente adotado, de utilização de recortes regionais únicos. No plano nacional, a Política Nacional de Desenvolvimento Regional (PNDR) se constitui em um exemplo formalizado dessa estratégia, agregando múltiplas escalas de ação de acordo com os problemas a serem enfrentados em cada território. No Rio Grande do Sul, essa forma de organizar as políticas regionais também foi adotada e, atualmente, tem como referência a organização dos Conselhos Regionais de Desenvolvimento (COREDEs), utilizando como escala complementar para o planejamento territorial as Regiōes Funcionais de Planejamento (CARGNIN, 2014).

Concebidos como fóruns de discussão e decisão a respeito de políticas e açôes que visam o desenvolvimento regional, os COREDEs foram criados oficialmente pela Lei 10.283 de 17 de outubro de 1994, que em seu artigo $2^{\circ}$, apresenta os objetivos destes conselhos, quais sejam: a melhoria da qualidade de vida da população, a promoção do desenvolvimento regional harmônico e sustentável, a distribuição equitativa da riqueza produzida, o estímulo à permanência do homem na sua região, a integração dos recursos e das açôes do governo na região e a preservação e a recuperação do meio ambiente (ESTADO DO RIO GRANDE DO SUL, Lei 10.283 de 17 de outubro de 1994).

Ante o exposto, este trabalho tem como objetivo realizar uma análise temática com o propósito de abordar o desenvolvimento regional e as estratégias de desenvolvimento construídas no Fórum de Discussão do COREDE Missóes. 


\section{METODOLOGIA}

Este estudo caracteriza-se como pesquisa qualitativa, ancorada na técnica Análise Temática (Braun e Clarke, 2006), para análise dos dados, os quais foram coletados em diferentes materiais, como livros, artigos publicados em periódicos e base de dados, a fim de abordar a temática do desenvolvimento regional a partir das estratégias de desenvolvimento construídas no Fórum de Discussão do COREDE Missões.

A Análise Temática constitui-se de uma técnica de análise qualitativa que "não é apegada a qualquer arcabouço teórico pré-existente e, por conseguinte, ela pode ser utilizada em diferentes quadros teóricos, e pode ser usada para fazer coisas diferentes dentro deles" (BRAUN; CLARKE, 2006, p. 81).

\section{REFERENCIAL TEÓRICO}

Nesta seção serão apresentados alguns dos referenciais utilizados como base teórica para a elaboração deste estudo. Inicialmente é preciso apresentar o conceito de desenvolvimento regional, para então, trazer a realidade da estrutura regional estabelecida no estado do Rio Grande do Sul, por meio dos COREDEs e por fim refinando o estudo com a exposição da realidade do COREDE Missóes comparado aos demais COREDEs da região funcional 7 específicamente.

\subsection{Desenvolvimento Regional}

Ao projetar o desenvolvimento regional é fundamental pensar "a participação da sociedade local no planejamento contínuo da ocupação do espaço e na distribuição dos frutos do processo de crescimento" (OLIVEIRA e LIMA, 2003, p. 31). Para os autores, as teorias que abordam o desenvolvimento regional originam-se da ideia de uma força motriz exógena que através de reaçóes em cadeia exercem influência sobre as demais atividades econômicas que impulsionam o desenvolvimento de uma região.

Trata-se de um processo complexo, que implica mudanças não somente de ordem política e econômica, mas principalmente, humana e social. Para Oliveira (2002), desenvolvimento é sinônimo de crescimento, acréscimo positivo no produto e na renda, transformando para satisfazer as necessidades do ser humano.

Já para Boisier (1996) o desenvolvimento regional requer um processo de fortalecimento da sociedade civil, indivíduos e região. Para este autor:

Uma concepçáo atualizada e contemporânea do desenvolvimento regional leva a reconhecer que se trata de um processo em curso com três cenários interdependentes e de recente configuração: há um cenário contextual, um cenário estratégico e um novo cenário político. O novo cenário contextual é o resultado da interação de dois notáveis processos que estão, atualmente, presentes em todos os países. Trata-se do processo de abertura externa, impelido pela força da globalizaçáo, e do processo de abertura interna, por sua vez impulsionado pela força da descentralização. O primeiro é um processo essencialmente econômico, enquanto o segundo é um processo político. (BOISIER, 1996) 
Conforme o autor, pode-se observar que o que importa é que com a organização do território, foi possibilitada a busca pela competência e competitividade. Essa reconfiguração do cenário tem propiciado ambientes organizacionais mais propícios a sistemas descentralizados de tomada de decisóes.

Ao valorizar a sociedade civil local, sua organização e relação social no processo de desenvolvimento, permite-se que a regiáo alcance um crescimento equilibrado e sustentado a longo prazo, sem conflito direto com a base social e cultural da regiáo (BARQUERO, 2001). Para o mesmo autor, este processo abrange três aspectos (econômico, sociocultural e político). No econômico, há sistema específico de produção capaz de assegurar o uso eficiente dos fatores produtivos e melhoria dos níveis de produtividade, com vistas a garantia de competitividade; no aspecto sociocultural têm-se a expectativa de os atores econômicos e sociais serem integrados às instituiçôes locais a fim de formar um sistema de relaçóes, que incorpore os valores da sociedade ao processo de desenvolvimento; e o político é materializado por iniciativas locais, que possibilitam a criação de um entorno local que incentiva a produção e favorece o desenvolvimento (BARQUERO, 2001).

O que percebe-se é que esta teoria do desenvolvimento, refere-se a um contraponto à insatisfação oriunda do esgotamento do modelo de desenvolvimento "a partir de fora" proposto nos anos 60 e 70. Bandeira (1999) corrobora destacando a evidente inadequação das açóes e políticas formuladas "de cima para baixo", ou seja, sem o envolvimento dos diferentes atores sociais. $\mathrm{O}$ autor ainda menciona que "a ausência de uma interação suficiente com os segmentos relevantes da sociedade tende a fazer que muitas das açóes públicas sejam mal calibradas, tornando-se incapazes de alcançar integralmente os objetivos propostos" (BANDEIRA, 1999, p.12). Assim, pode-se inferir que ao tratar a sociedade como objeto e náo como sujeito do processo de desenvolvimento, podem ocorrer ineficiências na implementaçáo de programas e políticas públicas, fazendo com que os resultados esperados não sejam atingidos e consequentemente podendo acarretar em maiores desigualdades.

\subsection{A regionalizaçáo do território do Rio Grande do Sul através da instituição dos COREDEs}

A questáo teórica acerca da temática da regionalização é clássica no planejamento e na economia regional, abrangendo a gestão pública de forma ampla. Para Büttenbender, Siedenberg e Allebrandt (2011):

\footnotetext{
As articulações para o desenvolvimento de regióes, seja em países, estados, ou fraçóes subnacionais, identificadas também como territórios, está se dando, cada vez mais, mediante a descentralização político-administrativa dos processos de planejamento e gestão territorial (BÜTTENBENDER, SIEDENBERG, ALLEBRANDT, 2011, p. 82).
}

No estado do Rio Grande do Sul, de acordo com De Toni e Klarmann (2002), o Programa Estadual de descentralização Regional objetivou definir a regionalização do território gaúcho e implantar a descentralização das atividades setoriais da Administraçáo Estadual direta e indireta, baseando-se em regiôes territoriais. Ao final da década de 1980, o debate sobre este assunto foi estimulado, resultando em 1989 na elaboração e aprovação da 


\section{Constituição Estadual (CONSTITUIÇÃO DO ESTADO DO RIO GRANDE DO SUL,} Texto constitucional de 3 de outubro de 1989).

A CE/RS trata especificamente em seu Capítulo II da Política de Desenvolvimento Estadual e Regional, definindo no artigo 166 os objetivos desta Política, sendo eles:

\footnotetext{
I - a melhoria da qualidade de vida da população com desenvolvimento social e econômico sustentável;

II - a distribuição equitativa da riqueza produzida com redução das desigualdades sociais e regionais;

III - a proteção da natureza e a ordenação territorial, mediante o controle da implantação dos empreendimentos públicos e privados em cada região e o estímulo à permanência do homem no campo;

IV - a integração da organizaçáo, do planejamento e da execuçáo das funçôes públicas de interesse comum de uma mesma região, nos termos dos arts. 16, 17 e 18 desta Constituição; $\mathrm{V}$ - a integração e a descentralização das açóes públicas setoriais em nível regional, através do planejamento regionalizado (CONSTITUIÇÃO DO ESTADO DO RIO GRANDE DO SUL, Texto constitucional de 3 de outubro de 1989).
}

Posteriormente, o artigo 167 da CE/RS, estabelece que a definição das diretrizes globais, regionais e setoriais da política de desenvolvimento caberá a órgão específico, com representação paritária do Governo do Estado e da sociedade civil, através dos trabalhadores rurais e urbanos, servidores públicos e empresários, todos eleitos em suas entidades representativas. $\mathrm{O}$ artigo seguinte, delibera que o sistema de planejamento garantirá mecanismos que assegurem ao cidadão o acesso às informaçóes sobre qualidade de vida, meio ambiente, condiçóes de serviços e atividades econômicas e sociais, bem como a participação popular no processo decisório.

Neste cenário é que os COREDEs foram sendo estruturados a partir do ano de 1991, instituídos legalmente pela Lei Estadual n ${ }^{\circ} 10.283$, de 17 de outubro de 1994, e regulamentados através do Decreto ${ }^{\circ}$ 35.764, de 28 de dezembro de 1994. Atualmente, estão oficialmente instituídos 28 COREDEs no Estado do RS, conforme o Quadro 1.

Quadro 1 - COREDEs do RS e número de municípios de abrangência

\begin{tabular}{|l|c|l|c|}
\hline \multicolumn{1}{|c|}{ COREDE } & $\begin{array}{c}\text { No atual de } \\
\text { Municípios }\end{array}$ & \multicolumn{1}{c|}{ COREDE } & $\begin{array}{c}\text { No atual de } \\
\text { Municípios }\end{array}$ \\
\hline Alto da Serra do Botucaraí & 16 & Missóes & 25 \\
\hline Alto Jacuí & 14 & Nordeste & 19 \\
\hline Campanha & 7 & Noroeste Colonial & 11 \\
\hline Campos de Cima da Serra & 10 & Norte & 32 \\
\hline Celeiro & 21 & Paranhana - Encosta da Serra & 10 \\
\hline Central & 19 & Produção & 23 \\
\hline Centro Sul & 17 & Serra & 31 \\
\hline Fronteira Noroeste & 20 & Sul & 22 \\
\hline Fronteiro Oeste & 13 & Vale do Caí & 19 \\
\hline Hortênsias & 7 & Vale do Rio da Várzea & 17 \\
\hline
\end{tabular}




\begin{tabular}{|l|c|l|c|}
\hline \multicolumn{1}{|c|}{ COREDE } & $\begin{array}{c}\text { No atual de } \\
\text { Municípios }\end{array}$ & \multicolumn{1}{c|}{ COREDE } & $\begin{array}{c}\text { No atual de } \\
\text { Municípios }\end{array}$ \\
\hline Jacuí-Centro & 7 & Vale do Rio dos Sinos & 14 \\
\hline Litoral Norte & 21 & Vale do Rio Jaguari & 9 \\
\hline Médio Alto Uruguai & 23 & Vale do Rio Pardo & 23 \\
\hline Metropolitano do Delta do Jacuí & 10 & Vale do Taquari & 36 \\
\hline
\end{tabular}

Fonte: Fórum dos COREDEs do RS, 2005.

Estes COREDEs estão articulados em nove regióes funcionais de planejamento (RF), proposto pela Secretaria de Coordenação e Planejamento do Estado do RS (ESTADO DO RIO GRANDE DO SUL, 2005), conforme apresentado na Figura 1, preocupando-se com as desigualdades regionais no Estado.

Figura 1 - Mapa das Regióes Funcionais

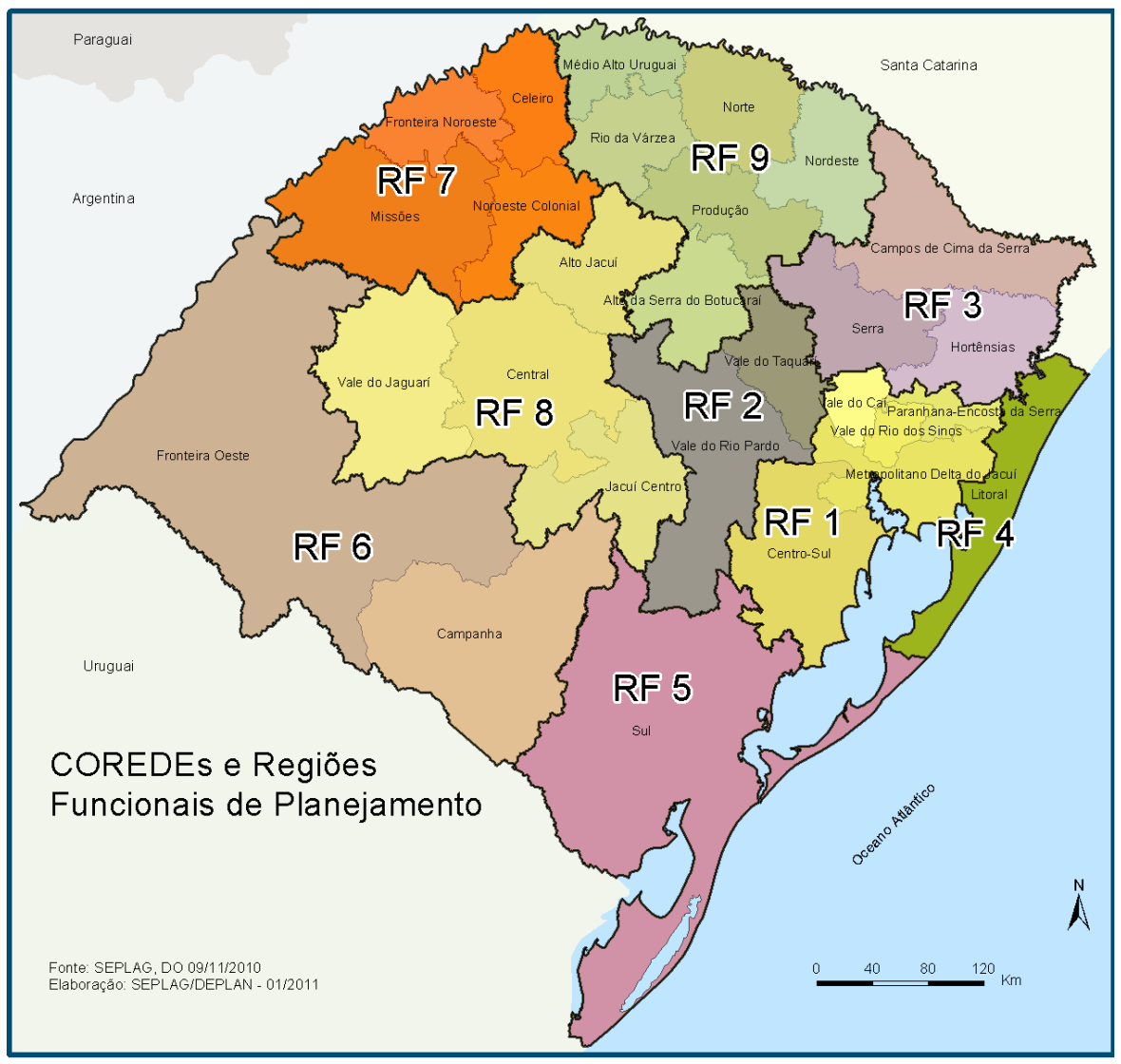

Fonte: SEPLAG - Secretaria de Planejamento e Gestáo do Estado do RS, 2010.

O COREDE Missóes pertence a RF 7, que engloba ainda as regióes Fronteira Noroeste, Celeiro e Noroeste Colonial, cada qual com características distintas, que contribuem para o processo do desenvolvimento da regiáo. 


\subsection{O COREDE Missóes comparado ao COREDEs da Regiáo Funcional 7}

A base econômica do COREDE Missóes está voltada à Agropecuária, destacando-se a criação de suínos e bovinos, além do cultivo de soja, milho, trigo e mandioca. Com pouca participação, a Indústria está ligada ao beneficiamento de produtos primários. Merece destaque também, o turismo histórico e cultural, com os sítios arqueológicos remanescentes das Reduções Jesuíticas de São João Batista, em Entre-Ijuís; de São Lourenço, em São Luiz Gonzaga; de São Miguel das Missóes e de São Nicolau (ESTADO DO RIO GRANDE DO SUL, 2015).

Ao que se refere aos indicadores sociais, o que preocupa é a saúde, a geração e apropriação de renda. A educação, mesmo detendo importante percentual da população adulta com Ensino Fundamental incompleto, se encontra em posição melhor aos demais COREDEs. A infraestrutura de transportes é deficiente, sendo que cinco municípios ainda não tem acesso asfáltico. A infraestrutura de saneamento também apresenta deficiências, principalmente no número de banheiros ou sanitários ligados à rede geral de esgoto ou fossa séptica (ESTADO DO RIO GRANDE DO SUL, 2015).

No ano de 2012, o Índice de Desenvolvimento Socioeconômico (IDESE) do COREDE Missóes foi de 0,721, situando-se no Nível Médio de desenvolvimento e na décima sexta posição no ranking dos 28 COREDEs. Todos os municípios se encontram no Nível Médio de desenvolvimento, destacando-se favoravelmente no ranking estadual, São Pedro do Butiá $(0,786)$, Cerro Largo $(0,781)$, Salvador das Missões $(0,777)$ e Santo Ângelo $(0,745)$, os quais possuem valores de IDESE maiores que a média do Estado (ESTADO DO RIO GRANDE DO SUL, 2015).

No Quadro 2, é possível observar os índices dos COREDEs da RF7, as respectivas Rendas per capita e seus ranqueamentos com relação aos 28 COREDEs do Estado.

Quadro 2 - Dados dos COREDEs da Regiáo Funcional 7

\begin{tabular}{|c|l|c|c|l|c|}
\hline \multicolumn{7}{|c|}{ Dados dos COREDEs - 2012 } \\
\hline $\begin{array}{c}\text { Regiáo } \\
\text { Funcional }\end{array}$ & \multicolumn{1}{|c|}{ Nome } & IDESE & Ranking & Renda per capita & Ranking \\
\hline \multirow{3}{*}{ RF7 } & Fronteira Noroeste & 0,767 & $8^{\circ}$ & $\mathrm{R} \$ 24.560,00$ & $11^{\circ}$ \\
\cline { 2 - 6 } & Missóes & $\mathbf{0 , 7 2 1}$ & $\mathbf{1 6}^{\mathbf{o}}$ & $\mathbf{R} \mathbf{1 8 . 5 8 2 , 0 0}$ & $\mathbf{1 9}^{\mathbf{o}}$ \\
\cline { 2 - 7 } & Noroeste Colonial & 0,792 & $3^{\circ}$ & $\mathrm{R} \$ 26.451,00$ & $7^{\circ}$ \\
\cline { 2 - 7 } & Celeiro & 0,719 & $17^{\circ}$ & $\mathrm{R} \$ 16.918,00$ & $26^{\circ}$ \\
\hline
\end{tabular}

Fonte: Elaborado pelos autores.

Por mais que alguns municípios do COREDE Missóes possuam um IDESE acima da média do Estado nenhum município atinge o mesmo valor do índice do COREDE Noroeste Colonia, que com um IDESE de 0,792 ocupa a $3^{\circ}$ posição entre os COREDEs do Estado.

No que se refere a renda per capita o COREDE Missôes cai para $19^{\circ}$ posição, com o valor de R \$ 18.582,o de renda per capita anual. O pior posiçâo entre os COREDEs da RF7 
fica a cargo do COREDE Celeiro que ocupa a antepenúltima posição com renda per capita anual de $\mathrm{R} \$ 16.918,00$.

Para verificar como se comportou a economia e o desenvolvimento dos municípios que fazem parte do COREDE Missóes analisou-se a evolução do Produto Interno Bruto (PIB) e do Valor Adicionado Bruto (VAB) dos segmentos agropecuária, indústria, serviços e administração pública no período de 1999 a 2013, cuja evolução encontra-se no Gráfico 1.

Gráfico 1. Evolução do PIB e do VAB no COREDE Missōes

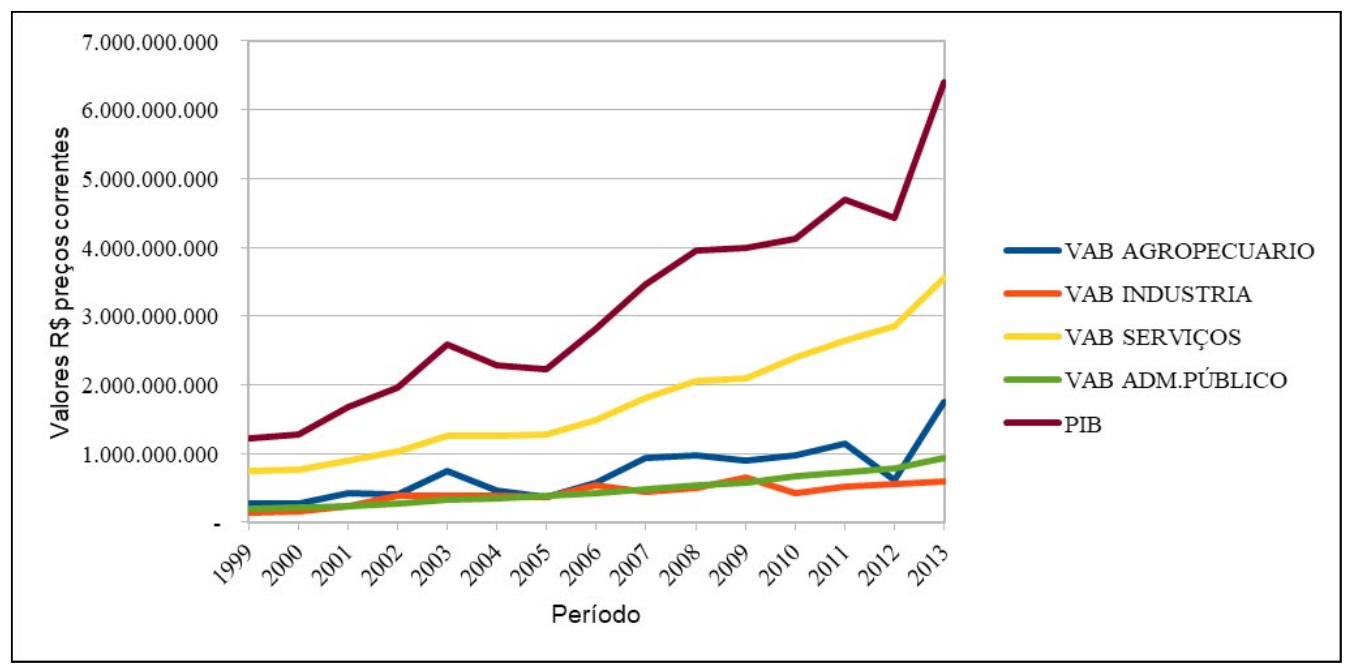

Fonte: Elaborado pelos autores.

Verifica-se que no COREDE Missóes o PIB cresceu em torno de $20 \%$ no período, onde houve crescimento constante até 2003, decrescimento entre 2003 e 2005 e após esse período recuperou-se, principalmente entre 2005 a 2008 e 2012 a 2013. O VAB Agropecuário apesar de não obter a maior contribuição no PIB, comportou-se de maneira semelhante a este, supondo-se que eles estáo relacionados diretamente. Pode-se ainda verificar, que entre os quatro segmentos analisados, é o VAB Serviços que possui maior participação no VAB Total, além disso, o mesmo não apresentou quedas significativas nos períodos de decrescimento do PIB (2003 a 2005), mantendo crescimento estável em virtude da compensação promovida pela indústria e administração pública.

Os referenciais estratégicos para promoção do desenvolvimento no âmbito do COREDE Missões foram construídos em assembleias regionais deliberativas, com a participação de representação da sociedade civil organizada, entidades governamentais e universidades, que inicialmente realizaram um diagnóstico da região e elaboraram a Matriz FOFA, para identificar as fraquezas e as potencialidades da região, a qual serviu de base para o processo de planejamento regional. O Quadro 3 apresenta a Matriz: 


\begin{tabular}{|c|c|}
\hline Fortalezas (fatores internos) & Oportunidades (fatores externos) \\
\hline $\begin{array}{l}\text { Disponibilidade energética com capacidade para } \\
\text { ampliaçáo de plantas industriais; } \\
\text { Existência de rodovias asfaltadas ligando a regiáo com } \\
\text { outras regióes no RS e MERCOSUL; } \\
\text { Boa oferta para ingresso ao ensino superior; } \\
\text { Proximidade aos mercados do MERCOSUL; } \\
\text { Existência de patrimônio histórico e cultural } \\
\text { reconhecido pela UNESCO; } \\
\text { Disponibilidade de mão de obra qualificada, } \\
\text { especialmente nos setores de serviços e comércio; } \\
\text { Alta produção na cadeia do leite; } \\
\text { Terras férteis facilitando à diversificação agrícola; } \\
\text { Posiçáo geográfica com alta densidade para o } \\
\text { armazenamento de energia solar e dos ventos; } \\
\text { Existência de universidades, polos tecnológicos, } \\
\text { escolas técnicas e centros de ensino; } \\
\text { Significativo número de propriedades da agricultura } \\
\text { familiar. }\end{array}$ & $\begin{array}{l}\text { Crescimento de integraçáo global das redes } \\
\text { tecnológicas; } \\
\text { Existência de financiamentos governamentais para } \\
\text { programas e projetos de empreendedorismo e } \\
\text { capacitação empresarial; } \\
\text { Expansão dos mercados continentais/MERCOSUL; } \\
\text { Estar inclusa no programa federal das mesorregiōes; } \\
\text { Aumento do capital social pela densidade da } \\
\text { organizaçáo social; } \\
\text { Investimentos em plantas industriais agrícolas para a } \\
\text { transformação de grãos, especialmente de soja, trigo } \\
\text { e milho; } \\
\text { Aumento dos recursos federais de financeiros à } \\
\text { modernizaçáo agrícola (Programa Mais Alimentos); } \\
\text { Financiamento de estruturas para a captação e } \\
\text { armazenamento de águas pluviais; } \\
\text { Revitalizaçáo e ampliaçáo da malha ferroviária } \\
\text { existente na região; } \\
\text { Existência de programas para a melhoria no } \\
\text { atendimento à saúde em todos os níveis. }\end{array}$ \\
\hline $\begin{array}{l}\text { Fraquezas (fatores internos) } \\
\text { Deficiente infraestrutura na maioria das propriedades } \\
\text { agrícolas para suportar períodos de estiagens/secas; } \\
\text { Elevado custo dos transportes para o mercado externo } \\
\text { em razão da distância dos portos de exportação; } \\
\text { Baixa produção de alimentos e derivados de agro } \\
\text { industrialização; } \\
\text { Inexistência de um banco de projetos estruturantes ao } \\
\text { desenvolvimento regional; } \\
\text { Base econômica em modelo agrícola exportador de } \\
\text { produção primária (grãos), sem agregação de valor na } \\
\text { cadeia de transformação e comercialização; } \\
\text { Baixos investimentos em pesquisa para as energias } \\
\text { limpas e renováveis. }\end{array}$ & $\begin{array}{l}\text { Ameaças (fatores externos) } \\
\text { Falta de políticas governamentais específicas para as } \\
\text { regiôes com baixo PIB, principalmente em pesquisas } \\
\text { tecnológicas; } \\
\text { Historicamente a região apresenta períodos com } \\
\text { instabilidades climáticas e frustraçóes de safras; } \\
\text { Condicionamentos impostos à diversificaçáo agrícola } \\
\text { e manutenção da monocultura de grãos; } \\
\text { Forte dependência da compra externa de insumos } \\
\text { necessários à produçáo agrícola; } \\
\text { Contaminaçấo do solo e das águas fluviais pela falta } \\
\text { de cuidados preventivos no uso de agrotóxicos; } \\
\text { Migraçáo de jovens qualificados, especialmente } \\
\text { técnicos de ensino médio e nível superior completo, } \\
\text { para outras regióes com maior oferta de trabalho. }\end{array}$ \\
\hline
\end{tabular}

Fonte: COREDE Missóes(2017, p.59-60).

Considerando as potencialidades da região, elencadas não somente na matriz FOFA, mas também no Estudo de Desenvolvimento Regional e Logística do RS (Rumos 2015), os Cadernos de Regionalização do PPA 2016-2019, os Planos Estratégicos dos COREDEs, o Atlas Socioeconômico do RS e o RS 2030, foram elencadas iniciativas promissoras para o desenvolvimento regional, quais sejam: aumento da produtividade da agropecuária e desenvolvimento de agroindústrias, por meio do incentivo à pesquisa eà inovação tecnológica, principalmente voltada ao aumento da produtividade da lavoura empresarial, irrigação das 
culturas e desenvolvimento de novos cultivares, considerando que as agroindústrias podem contribuir para a agregação de valor aos produtos; fomento ao turismo regional, valorizando a presença dos sítios arqueológicos remanescentes das Reduçóes Jesuíticas; e, integração global das redes tecnológicas.

Por outro lado, as questóes que devem ser tratadas com atenção dizem respeito a qualificação da infraestrutura de transportes, pois a região é marcada pelas grandes distâncias da capital, dos portos e dos principais centros consumidores do Estado e até mesmo a precariedade de infraestrutura da faixa de fronteira, além de que cinco dos vinte e cinco municípios nem mesmo possuem acesso asfáltico: Eugênio de Castro, Garruchos, Pirapó, Rolador e Ubiretama; aos baixos indicadores de saneamento; as secas e estiagens periódicas e as mudanças na estrutura etária da população e migraçóes.

No comparativo do COREDE Missōes com os COREDEs da RF7 percebe-se uma concentração de um polo industrial nos COREDEs Fronteira Noroeste (Santa Rosa e Horizontina) e Noroeste Colonial (Ijuí e Panambi), sendo que o primeiro é voltado a produção de máquinas e equipamentos e o segundo voltado a indústria de processamento e produção de produtos alimentícios.

O Planejamento Estratégico de Desenvolvimento da Região está pautado em quatro bases que foram definidas por meio de articulação "estatal e regional, com ampla participação dos atores locais regionais", tornando-se as diretrizes estratégicas para a Região Funcional 7 pautado nas seguintes prioridades:

- Qualificação da infraestrutura logística, energética e de comunicação na regiáo.

- Qualificaçáo, agregaçáo de valor e aumento da competitividade das cadeias produtivas, através de investimentos na inovação, empreendedorismo, ciência e tecnologia.

- Qualificação da governança territorial (regional), com investimentos na capacitação de gestores públicos, privados e comunitários, fortalecendo a cooperação inter e supraregional (UNISC, 2017).

Merece destacar ainda mais especificamente o projeto 4 do Planejamento Estratégico em questão, que visa investir até $\mathrm{R} \$ 70.000 .000,00$ (setenta milhóes), no fortalecimento da Ciência, Tecnologia e Educação na Região Funcional 7, por meio da geração de um Parque Tecnológico do Noroeste Gaúcho e Ecossitema Inovador, cuja responsabilidade de implantação se dará pela articulação entre Secretaria de Desenvolvimento Econômico, Ciência e Tecnologia, Ministério da Ciência e Tecnologia, Universidade, Parques Científicos e Tecnológicos entre outros segmentos regionais ligados a inovação e tecnologia (UNISC, 2017).

O projeto 4 incorpora e aproxima as Universidades no processo de articulação social para a execução do projeto por meio das ações de extensão universitárias de formação ou por meio de incubadoras inovadores e tecnológicas mais notadamente. Neste sentido a implantaçáo mais recente da Universidade Federal da Fronteira Sul no município de Cerro Largo, situado no COREDE Missóes em parceria com as demais Instituições de Ensino Superior comunitárias e particulares já consolidadas na região, podem tornar-se mecanismo propulsor da melhoria dos índices sociais do COREDE Missóes. 


\section{CONSIDERAÇÓES FINAIS}

É fundamental considerar que o processo de desenvolvimento não se dá de forma homogênea e que dentro de um único território podem haver desigualdades, em razão do próprio desenvolvimento que muitas vezes se concentra em um único local. Isso ocorre devido a afirmação do mercado global que fez com que as grandes empresas ignorassem os governos nacionais e passassem a promover disputas entre os governos locais em busca das melhores vantagens para seus projetos de expansão.

No final da década de 90 houve uma percepçáo por parte das esferas governamentais de que o desenvolvimento se gerido unicamente pelas regras do mercado privilegiaria apenas territórios com vantagens competitivas acentuando assim a distância entre as regióes. Neste sentido o RS retoma a questão em 98 com a Política Estadual de Desenvolvimento e outras que se seguiram. No âmbito nacional destaca-se a Política Nacional de Desenvolvimento Regional que organizou as estratégias de intervenção do Estado maior nos territórios para a redução das desigualdades, surgindo com isso o Programa de Desenvolvimento da Faixa de Fronteira (PDFF) e o Programa de Promoção da Sustentabilidade de Espaços Sub-Regionais (PROMESO) (CARGNIN, 2014).

A Política de Desenvolvimento Regional de 1998, elaborada com o objetivo de incentivar o desenvolvimento mais equilibrado e reduzir as desigualdades regionais, estabeleceu uma tipologia de renda, definiu instrumentos para a descentralizaçáo industrial, criou um fundo estadual para o desenvolvimento regional e, aproveitando a institucionalidade dos COREDEs, lançou a Consulta Popular como instrumento de participação e promoção do equilíbrio regional, consolidando-se como uma boa prática de gestâo pública e exercício da cidadania.

As políticas destinadas ao desenvolvimento regional e, em especial, das regióes menos desenvolvidas, tornam perceptível a valorização da questão regional na escala nacional e das unidades federativas. Tal fato se manifesta em documentos que orientam o planejamento nas diferentes esferas do Poder Público, no universo acadêmico e nos projetos e estratégias desenvolvidos pelos setores não governamentais.

Neste sentido, Bandeira (1999) elucida que apesar dos resultados positivos já atingidos através da atuação dos COREDES, ainda existe um caminho a ser trilhado para que se possa afirmar que as potencialidades dos mesmos estáo sendo adequadamente exploradas, provocando a articulação dos atores sociais das regióes, bem como a intermediação entre a comunidade e a esfera pública.

Em algumas regiōes a atuação dos COREDES na articulação da sociedade regional, ocupa um espaço bem mais significativo que em outras (BANDEIRA, 1999). A estrutura de cada Conselho Regional, seu quadro técnico, os estudos e interesses políticos interferem neste desempenho, considerando que todos os COREDES possuem dificuldades operacionais semelhantes, dentre elas, o repasse de recursos para a manutenção de suas atividades. Considerando estas dificuldades, o aporte técnico das universidades auxilia significativamente no desempenho das atividades promovidas pelos COREDEs (BÜTTENBENDER; SIEDENBERG; ALLEBRANDT, 2011). 
Assim, os Conselhos Regionais que recebem maior apoio das Universidades locais tem assegurado maior credibilidade para seu trabalho, uma vez que encaram estas atividades como um instrumento de integração com a comunidade e regiáo de atuação, ao passo que nas regióes em que não existem Universidades, existe um menor engajamento e consequentemente o trabalho dos Conselhos enfrenta maiores dificuldades (BANDEIRA, 1999). No caso do COREDE Missóes, o suporte das universidades impacta positivamente, pois em sua regiâo de abrangência encontram-se instaladas e atuantes universidades privadas, bem como uma universidade federal (UFFS), conquistada inclusive através de políticas públicas que visam o desenvolvimento da região.

\section{REFERÊNCIAS}

ATLAS SÓCIO ECONÔMICO DO RS. COREDES. Disponível em: <https:// atlassocioeconomico.rs.gov.br/conselhos-regionais-de-desenvolvimento-coredes $>$. Acesso em: 1 nov. 2017.

\section{BANDEIRA, Pedro. Participaçáo, Articulação de Atores Sociais e Desenvolvimento}

Regional. Texto para discussão no630. IPEA: Brasília, 1999. Disponível em: <http://www. ipea.gov.br/agencia/images/stories/PDFs/TDs/td_0630.pdf>. Acesso em: 01 nov. 2017.

\section{BARQUERO, Antonio Vasquez. Desenvolvimento endógeno em tempos de} globalização. Porto Alegre: FEE/UFRGS, 2001. 278p.

BOISIER; Sérgio. Em busca do esquivo desenvolvimento regional: entre a caixa-preta e o projeto político. In: Planejamento e políticas públicas. no 13 - jun. de 1996. p. 111-143.

BRAUN, V.; CLARK, V. Using thematic analysis in psychology. Qualitative Research, v. 3, n. 2, p. 77-101, 2006.

BÜTTENBENDER, P. L; SIEDENBERG, D. R; ALLEBRANDT, S. L. Conselhos Regionais de Desenvolvimento (COREDES) RS: Articulaçóes Regionais, Referenciais Estratégicos e Consideraçóes Críticas. Revista Desenvolvimento Regional em Debate. Canoinhas - SC, ano 1, n. 1, dez. 2011.

CARGNIN, Antonio Paulo. Políticas de desenvolvimento regional no Rio Grande do Sul: vestígios, marcas e repercussóes territoriais. $1^{\text {a }}$. ed. - Brasília, DF: Ministério da Integração Nacional, 240 p., 2014.

COREDE Missões. Planejamento Estratégico. Disponível em: <http://www2.al.rs.gov.br/forumdemocratico/LinkClick. aspx? fileticket $=9$ Urkjjeva2g\%3D\&tabid $=5363 \& \mathrm{mid}=7972>$. Acesso em: 01 novembro 2017. 
DE TONI, Jackson; KLARMANN, Herbert. Regionalização e Planejamento, reflexões metodológicas e gerenciais sobre a experiência gaúcha. Revista Ensaios FEE, Porto Alegre, v.23, n. especial, p. 517-538, 2002.

OLIVEIRA; Gilson Batista de. Uma discussão sobre o conceito de desenvolvimento. Revista FAE, Curitiba, v.5, n.2, p.37-48, maio/ago. 2002.

OLIVEIRA; Gilson Batista de; LIMA; José Edmilson de Souza. Elementos endógenos do desenvolvimento regional: consideraçóes sobre o papel da sociedade local no processo de desenvolvimento sustentável. Revista FAE, Curitiba, v.6, n.2, p.29-37, maio/dez. 2003.

Planos estratégicos de desenvolvimento dos COREDEs 2015-2030: perspectivas estratégicas das Regióes Funcionais / Lajeado : Ed. da Univates, p. 117-139, 2017. Disponível em: <http://planejamento.rs.gov.br/upload/arquivos/201710/09144414plano-sintesers.pdf>. Acessado em: 20 set. 2018.

PPA Participativo Região Funcional 7 - Perfil 2011. Disponível em: <http://www2.unijui. edu.br/ - coredefn/Plano_Estrategico_Regiao_Fronteira_Noroeste/PPA-ParticipativoRegi\%C3\%A3o\%20Funcional\%207-Perfil-2011.pdf>. Acesso em: 7 nov. 2017.

\section{PRÓ-RS V. Propostas estratégicas para o desenvolvimento regional do Estado do}

Rio Grande do Sul (2015-2018). Conselhos Regionais de Desenvolvimento (Coredes), Lajeado: Editora da Univates, 160 p., 2014. Disponível em: <http://www.coredesul.org. br/files/pub/140533851196675_Pro-RS-V_web-1-.pdf>. Acesso em: 7 nov. 2017.

RESENDE, G. M. Elementos do desenvolvimento regional: temas atuais, desafios e oportunidades da questão regional. In: SILVEIRA, R. L. L (org.) Observando o desenvolvimento regional brasileiro: processo, políticas e planejamento. Santa Cruz do Sul: EDUNISC, 2013.

RIO GRANDE DO SUL. Constituição (1989). Constituição do Estado do Rio Grande do Sul: promulgada em 3 de outubro de 1989. Disponível em: <http://www2.al.rs.gov. br/dal/LegislaCAo/ConstituiCAoEstadual/tabid/3683/Default.aspx>. Acesso em: 01 nov. 2017.

RIO GRANDE DO SUL. Governo do Estado do Rio Grande do Sul. Lei No 10.283, de 17 de outubro de 1994. Dispóe sobre a criação, estruturação e funcionamento dos Conselhos Regionais de Desenvolvimento e dá outras providências. Disponível em: <http://www.al.rs.gov.br/Legis/M010/M0100099.ASP?Hid_Tipo=TEXTO\&Hid_ TodasNormas $=12666 \&$ hTexto=\&Hid_IDNorma=12666>. Acesso em: set. 2017.

RIO GRANDE DO SUL. Governo do Estado do Rio Grande do Sul. Decreto No 35.764, de 28 de dezembro de 1994. Regulamenta a Lei no 10.283, de 17 de outubro de 1994, que criou os Conselhos Regionais de Desenvolvimento. Disponível em: 
<http://www.al.rs.gov.br/Legis/M010/M0100099.ASP?Hid_Tipo=TEXTO\&Hid_ TodasNormas $=12439 \&$ hTexto=\&Hid_IDNorma=12439>. Acesso em: set. 2017.

RIO GRANDE DO SUL-SCP. Rumos 2015: Estudo sobre o desenvolvimento regional e logística no Rio Grande do Sul (Documento Síntese). SCP/DEPLAN-DCAPET, Porto Alegre/SCP, 2006.

RIO GRANDE DO SUL. Governo do Estado do Rio Grande do Sul. Núcleo Regional de Integração da Faixa de Fronteira. Plano de Desenvolvimento da Faixa de Fronteira do Estado do Rio Grande do Sul - PDIF/RS. 2012. Disponível em: <http://planejamento. rs.gov.br/upload/arquivos/201604/11112501-pdif-rs-versao-final-site-relinter.pdf>. Acesso em: 10 out. 2017.

RIO GRANDE DO SUL. Governo do Estado do Rio Grande do Sul. Secretaria do Planejamento, Mobilidade e Desenvolvimento Regional. Departamento de Planejamento Governamental. Perfil Socioeconômico COREDE Missóes. 2015. Disponível em: <http://planejamento.rs.gov.br/upload/arquivos/201603/28140705-perfis-regionais-2015missoes.pdf>. Acesso em: set. 2017.

SEPLAG. Secretaria de Planejamento e Gestão do Estado do RS. Conselhos Regionais de Desenvolvimento. 